\title{
Poder e impoder de la muerte: al encuentro del escepticismo y el goce (concurrencias entre Jacques Lacan y G.W.F. Hegel)
}

\section{Power and impower of death: to the encounter of skepticism and enjoyment. (concurrences between Jacques Lacan y G.W.F. Hegel)}

Lorena Souyris Oportot ${ }^{1}$

Recibido: 31/07/2013 - Aceptado: 28/08/2013

\begin{abstract}
Resumen
El artículo es una tentativa para repensar, a partir de una frontera entre el psicoanálisis y la filosofía, el estatuto de la pulsión de muerte inscribiéndose, a partir de una confrontación entre intuiciones de Jacques Lacan y G.W.F. Hegel. En este diseño, el artículo se consagra como una exploración del «sentido» y las «posibilidades» de especulación alrededor de una ex-pulsión de muerte bajo una base escéptica en el significado lógico del término. Para ello, se propone, por una parte, explicar el lugar de la negatividad como aquello que da cuenta de la disolución y desaparición [l'Aufhebung] del sujeto del inconsciente. Y por otra parte, analizar el escepticismo como recurso para pensar la economía del goce lacaniano, en cuanto falta y disolución.
\end{abstract}

Palabras clave: Escepticismo - pulsión de muerte - goce - sujeto barrado del inconsciente - negatividad.

\begin{abstract}
Based on the boarders between psychoanalysis and philosophy, this article is an attempt to re-think the principle of the death drive by confronting
\end{abstract}

1 Chilena, Profesora de filosofía y licenciada en Educación por la Universidad Católica Silva Henríquez. Magister en estudios de género y cultura en América Latina, mención filosofía y humanidades por la Universidad de Chile. cursando la investigación doctoral en la Universidad París 8 Vincennes en cotutoría con la Universidad Complutense de Madrid, mediante beca CONICYT. Investigadora asociada de CENALTES. Actualmente se desempeña como académica de la Universidad Silva Henríquez y académica asociada por el programa de magíster en estudios interdisciplinarios de género CIEG. Facultad de Ciencias sociales, Universidad de Chile. Contacto: Iorena504@msn.com.; loreoportot@gmail.com. 
the approaches of Jacques Lacan and G.W.F. Hegel. This article explores "sense" and "possibilities" of speculation around and ex- death drive under a logic-sceptical meaning of these concepts. The article explains, on the one hand, the place of negativity as accounting for the dissolution and abolition [l'Aufhebung] of the unconscious subject; and on the other hand, it analysis scepticism as a resource to think the economy of Lacanian enjoyment.

Key words: Scepticism - death drive - enjoyment - abolition of the unconscious subject - negativity

\section{Introducción}

"Por el lado del «ser»viviente, llamado a la subjetividad, se manifiesta la pulsión". «La afanisis debe situarse en el nivel donde el sujeto se manifiesta en ese movimiento de desaparición»²:

El objetivo de introducir un diálogo entre Lacan y Hegel es para poder pensar en la posibilidad de dar una base escéptica, en sentido hegeliano, al estatuto de la pulsión de muerte desarrollado por Lacan. Y para desplegar esta idea, primero que todo se partirá dando una sucinta definición de la actividad de la negación. Su función, a grandes rasgos -y que a mi juicio es posible inscribirla en la operación significante de la estructura inconsciente, como lo que posibilita una enunciación escéptica- es de expresar, por una parte, la disolución, la desaparición o, específicamente la abolición [Aufhebung] del sujeto. Y, por otra parte, dar cuenta de la figura del «desconocimiento» en tanto una cierta «ignorancia» intrínseca que estructura al sujeto mismo.

De alguna manera, pues, explorar el significado psicoanalítico de la muerte a la luz del escepticismo, en tanto una categoría filosófica, es más bien, dar un nuevo giro interpretativo a la reflexión. Sondear sus posibilidades para intentar abrir otros caminos de búsqueda a partir de una re-vuelta inventada, pero también de un retorno retrospectivo.

Ahora bien, en lo que respecta al tema del desconocimiento, como lo que estructura al sujeto del inconsciente, es menester localizar el

2 LACAN, Jacques. El Seminario 11: Los cuatro conceptos fundamentales del psicoanálisis. Paidós Editorial, 1a ed. 18 reimp. Buenos Aires, 2011. Pág: 235-236. 
problema de dicha ignorancia, como la manera de operar del inconsciente, no solo a modo de inflexión del reconocimiento de parte del sujeto, sino también como manifestación de la dislocación interna que significa la escisión expresada a través del sujeto barrado o alienado. Esto revelaría, así, que la figura de la «ignorancia» sería el camino que recorre el significante para llegar a conocer «su verdad». En otros términos, el recorrido como la experiencia dentro del inconsciente mismo donde la cadena significante -el significante, luego de haberse relacionado dialécticamente con otro significante- procura su "extrañeza" [alienación] obligándose, el significante mismo, a transformar el comportamiento "habitual" de su saber. De suerte que comienza, así, a interiorizar y garantizar el concepto, su significado, como su verdad: la verdad del deseo de muerte y, por medio de esto, garantizar su sacrificio en tanto nulidad. He aquí el recorrido de desesperación y acción del escepticismo.

Para avanzar un poco más en aquello que nos ocupa, es necesario hacerse la pregunta por la posibilidad de una enunciación escéptica como modo de negación. Si bien, en Hegel, el escepticismo tiene relación no solo con la libertad de la autoconsciencia -donde residiría, también, el estoicismo y la conciencia desventurada, cuyas tres figuras de la conciencia de-sí constituyen los momentos dialécticos de dicha autoconciencia y, por lo mismo, una manera para la autoconciencia de vivir la relación a su esencia, es decir, a su negatividad absoluta-, también tiene relación con el método de la proposición especulativa.

En efecto, se dirá que la manera de vivir de parte de la autoconciencia es el modo de obrar de su propia libertad. Por lo que las tres figuras ya citadas, arrastran a la autoconciencia hacia su libertad. Esto daría cuenta del despliegue necesario, en el elemento del pensamiento, de la confrontación de la conciencia misma con su esencia interna, con su interioridad. Este enfrentamiento es con su esencia inmortal y cuyo método sería aquel de la proposición especulativa, que no es sino la actividad de la «reflexión especulativa» desplegada como "determinaciones-de-reflexión" ${ }^{3}$. et Pierre-Jean Labarrière. Editions Kimé, París, 2010. Pág: 33 [258]. 
"La autoconciencia escéptica experimenta en las mutaciones de todo cuanto trata de consolidarse para ella su propia libertad [...] la autoconciencia escéptica es para-sí esta ataraxia del pensamiento que se piensa a sí mismo; es, por tanto, ese desatino inconsciente que consiste en pasar a cada paso de un extremo a otro del extremo de la autoconciencia igual a sí misma al de la conciencia fortuita, confusa y viceversa. ${ }^{\prime \prime 4}$

Desde esta perspectiva, entonces, se podría sostener que si existe alguna cosa inmortal es precisamente la muerte, pero además e incluso esta esencia infinita puede ser pensada, particularmente, a la luz del escepticismo. En efecto, el escepticismo no es una simple posición sino, y a modo general, una contra-posición, una confrontación o, más bien, la actividad de presentar siempre el lugar contrario como teniendo el mismo valor de verdad a fin de traspasar los límites de lo «certero» luego de haber mostrado la posibilidad de lo «otro».

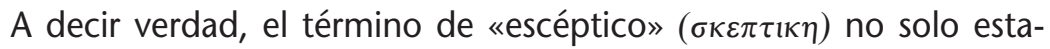
ría, etimológicamente, lié à l'idée de doute mais à l'idée d'examen $\left((\sigma \kappa \varepsilon \pi \tau \varepsilon \sigma 9 \alpha 1)^{5}\right.$, lo que expresaría, por una parte, la dinámica interna de la actividad dialéctica en el pensamiento pero, por otra parte, $y$ he aquí mi hipótesis, abre a la posibilidad de repensar la racionalidad del psicoanálisis. Ya que si bien, éste es un método que interpreta, en la clínica, el recorrido y retorno a un «antes impensado» y, por lo mismo, reprimido e «inter-dit» [entre-decir] dicho procedimiento, puede ser visto a la luz de un ejercicio escéptico, como el «examen» que fisura las categorías fijas del entendimiento y de lo que el individuo puede re-pensar con respecto de sí, en su proceso psicoanalítico, para poner en marcha una suerte de disolución del sujeto del inconsciente mismo. Todo esto, a través de un modo dialéctico en el pensar y solo posible recurriendo al ejercicio de la negatividad como el motor de dicha disolución y, también, como aquello que está en el "entre" del decir, a saber, en lo no-dicho. Es bajo esta operación que aparece el carácter trágico y la economía catártica del goce y la ex-pulsión de muerte.

\footnotetext{
4 HEGEL, G.W.F. La Fenomenología del espíritu. Fondo de Cultura Económica, 2da reimp. Bogotá, Colombia, 1993. Pág. 126.

5 QUENTIN, Bertrand. Hegel et le scepticisme. L'Harmattan, éditions, Paris, 2008. Pág. 14.
} 
Así y retomando tal consideración a propósito de la dialéctica, Hegel buscaría establecer un concepto de escepticismo interno a la razón, de manera que su acción negativa sea reconocida como un trazo [significante] propiamente racional y no la declaración final del saber deviniendo el vacío de "nada". En consecuencia, es desde ahí, que es posible comprender la fuerza de la destrucción e incluso de una suerte de "desastre de la enunciación" en tanto muerte del enunciado como el motor o la pulsión de la autoconsciencia y su "espíritu trágico".

Entonces, pues, la pregunta es ¿por qué un trabajo «etimológico» del concepto de escepticismo, para llegar a comprender aquello que Lacan problematiza en relación a la muerte? Muerte no solo inscrita como castración en la palabra que legitima la "lettre" en el inconsciente, sino también en el estatuto del sujeto en relación al significante. Una posible respuesta a esta interrogación podría tener dos acepciones lógicas, primeramente, para demostrar cómo ciertas nociones hegelianas, sobre todo el estatuto del escepticismo, ayudan a sostener una articulación común entre los dos autores que pueda producir una forma de re-apropiación y de re-significación de la categoría de muerte que vaya más allá de su régimen existencialista y, por lo mismo, finito. $Y$, luego, se presenta un problema que liga estrechamente a lo que toca a la filosofía y el psicoanálisis particularmente al psicoanálisis lacaniano.

De suerte que, a partir de estas dos acepciones, no sería posible considerar posiciones "definitivas", en general, en lo que concierne a las dos disciplinas $y$, específicamente, en lo que atañe a ciertas categorías que pueden tener la capacidad de ser reformuladas a la luz de entrecruzamientos y puntos de articulación. Puesto que aquello no ha sido solo practicado por Hegel -al final de su vida, él corregiría la "Science de la logique" y su proyecto era de hacer la misma cosa con la "Phenomenologie de l'Esprit-sino también por Lacan a lo largo de su obra. Por lo que la manera de proceder, en el primero, ha sido de fundar filosóficamente -partiendo por la puesta en marcha de redefinir el escepticismo en tanto la fuerza que disuelve las proposiciones fijas y dogmáticas como uno con la filosofía- el estatuto de la razón especulativa, lo que posibilitó ver en el escepticismo el elemento del pensamiento.

Por otra parte, en el segundo, se ha podido constatar un ritmo dialéctico, no solo de la manera que él ha abordado, transformado y 
disuelto las mismas nociones que han tenido una significación a través de ciertas influencias de sus contemporáneos, sino además, dicha dinámica dialéctica, ha permitido una movilidad y aún, una plasticidad en las ideas más esenciales del pensamiento francés contemporáneo. Lo que ha facilitado ver, también en Lacan, el ejercicio escéptico en su forma de hacer frente al saber racional psicoanalítico.

En esas condiciones, la tesis que yo sostengo es de intentar demostrar el régimen especulativo que existe en el rendimiento lógico del sistema significante que estructura la racionalidad del inconsciente. Efectivamente, debido a la extensión de este artículo, dicha tesis será solo enunciada, puesto que es parte de una investigación más prolongada. No obstante, es menester exponerla para poder clarificar la relación entre escepticismo, muerte, goce y negatividad, en cuanto categorías clave que giran alrededor de este escrito.

A decir verdad, es siempre en torno de una perspectiva especulativa racional -sea en el programa psicoanalítico lacaniano como en el programa sistemático hegeliano- que aparecen ciertos conceptos, tales como négation déterminée, scepticisme qui se consomme à soi lui- même, réflexion et mort absolue en Hegel et sujet barré, béance, signifiant/ signifié, jouissance, désir et mort en Lacan, donde es posible encontrar puntos en común y ver el problema del régimen del escepticismo hegeliano en relación al estatuto de la muerte en Lacan.

Si bien, el rendimiento de la negatividad -que niega, mantiene, transforma y hace desaparecer al sujeto de la enunciación, deviniendo, mas bien, en una manifestación escéptica- contiene y nos dirige a la muerte, es porque su actividad conlleva la imposibilidad, no solamente de acceder a la singularidad del significante en-sí mismo por su estatuto de borradura, sino también nos dirige a la oblación del significante en tanto el substrato o la traza huidiza que insiste sobre la dislocación de la "ley" de la cadena significante.

De suerte que es posible "examinar" (en el sentido etimológicamente escéptico) la escisión o falla, propia de "lo Real" lacaniano, que traduce el "sacrificio" de la singularidad concreta de la "unidad" particular del significante en-sí, en la medida donde este significante singular en-sí mismo, de sí-mismo y en estado "puro", nombra y ejerce la desapropiación y el desposeimiento de sí-mismo, precipitándose hacia 
lo otro-de-sí, hacia la alteridad y/o diferencia. He aquí la posibilidad de pensar su "unidad" particular como contenida en-sí de una contradicción que se niega a sí-misma.

"La relación del sujeto con el Otro se engendra toda en un proceso de hiancia [...] «La alienación consiste en ese «vel» que condena al sujeto a solo aparecer en la hiancia, es decir, que si aparece de un lado como sentido producido por el significante, del otro se inscribe como desaparición". ${ }^{6}$

En otros términos, el significante en-sí y de sí-mismo sacrifica su singularidad concreta donde su sacrificio supone la puesta en marcha de la muerte de su particularidad finita, revelando de esta manera, que el sacrificio "especulativo", en tanto una proposición, sería el hecho del devenir sacrificial propio del escepticismo, donde el sí-mismo de cada significante toma sobre sí-mismo, no la afirmación determinada de una muerte que se traduciría inmediatamente en vida y, a partir de esto, en pulsión, sino más bien, el reconocimiento que la muerte es y será siempre la suya propia o, aun, que la singularidad irremplazable de su muerte es la esencia misma de su sacrificio.

En consecuencia, establecida la hipótesis y enunciada la tesis en cuestión, primeramente, se abordará de manera más detallada el "alcance" del deseo en el inconsciente, su relación con la negación interna al juicio y con el rechazo propio de la pulsión. Luego, en un segundo punto se dará cuenta de la articulación entre escepticismo y goce y cómo, mediante el escepticismo, se instala el "cuestionamiento o la duda" que conduce al sujeto a establecer un trato con el des-tiempo de la experiencia analítica. En otros términos, con la temporalidad del inconsciente que no es sino el tiempo de la pulsión de muerte y las fronteras o límites del pensamiento.

\section{Lógicas paradójicas entre deseo y muerte}

Cuando Freud escribió La Interpretación de los sueños, cuyo nombre original es Traumdeutung, intentó localizar el vínculo estructural entre 
el sueño y los deseos. De esta manera, si el horizonte de sentido de la interpretación comporta una referencia irreductible al inconsciente, entendido éste como esfera de realización efectiva de deseos, ello no obsta para que el proceso deliberativo que subyace a dicha interpretación, ponga en juego categorías como represiones, resistencias y negaciones que incluso podrían no ajustarse inmediatamente al espacio de realización de los sueños. En este sentido debe hablarse de un intercambio recíproco -no carente de enfrentamientos- entre habla y pulsión, una fusión de horizontes que posibilita la actualización de ambas esferas, a saber, inconsciente e interpretación, conforme al devenir específico de cada sujeto hablante.

Ahora bien, desde aquella obra Freud se propuso diseñar un modelo explicativo de la acción de los deseos ligándola de manera indisoluble con la condición de los sueños de la racionalidad psicoanalítica del inconsciente. Para ello se presentarán los modos en que el autor se hace cargo de las nociones de pulsión, muerte, angustia y satisfacción, introduciéndolas como elementos constitutivos de la deliberación racional de los sueños en el inconsciente.

Desde esta perspectiva, cabe preguntarse a este respecto, ¿cómo es que Freud concibe el objeto de investigación propio de una reflexión sobre los sueños? La principal característica que Freud atribuye a los asuntos del inconsciente en el contexto de una investigación es que una ciencia que lo estudie deberá asumir y ser justa con su carácter inexacto. A pesar de que el modelo de la interpretación está íntimamente ligado a una producción deliberativa y hermenéutica, su fundamento en torno a los sueños se basa en una "racionalidad" en el sentido de la intervención de los reflejos mentales que son estructurados como y por el lenguaje. De esta manera, la lógica de la interpretación es precisamente deliberar en torno a los grados del discurso que estructura el sueño y los deseos inmersos allí, en cuanto son descifrados a través de materiales manifiestos y latentes. Esto no implica ni que solo intervengan factores racionales, por un lado, ni que tal racionalidad de la estructura deliberativa de la interpretación, en cuanto método, nos ponga en condiciones de establecer principios universales respecto a los sueños, los deseos y sus modos de operar a partir de los desplazamientos y las condensaciones, por el otro. 
De lo que se trata de decir es que la esfera de los procesos oníricos no puede ser objeto de una ciencia exacta debido, entre otras cosas, a su relación con el lenguaje. Además de que en dicha esfera no intervienen ni meros elementos racionales ni meros elementos psíquicos. Fundamentalmente el ámbito del inconsciente psicoanalítico se encuentra definido por la concurrencia de estos dos factores cada vez que tiene lugar la acción de los procesos oníricos, los cuales se encuentran situados en medio de una infinidad de elementos lenguajeros, repeticiones, deseos, etc. Esto torna imposible poder establecer una norma a priori o principio universal a aplicar en cada caso en la cura y su interpretación, especialmente, porque existe la incertidumbre respecto de los "resultados" de la acción de deseos y del deseo mismo. Es decir, incertidumbre en la esfera de las acciones producidas a partir de deseos, ya que el análisis de los deseos y su operación en los sueños, obedece a la esfera del quehacer humano; es por esto que no se la puede examinar como objeto de estudio exacto. De acuerdo con esto, entonces, uno de los componentes "esenciales" de la explicación de la acción libre y humana sería el factor desiderativo, es decir, la realización de los deseos en cuanto factor determinante para el ejercicio de la acción psíquica, materializada en actos humanos.

En la misma línea y retomando los presupuestos de Freud, uno de los aspectos más profundos y originales -en su época- de su teoría, consistió en haber analizado y complejizado la relación entre sueño y muerte. En efecto, se podría decir que Freud se resiste a marcar una diferencia externa entre deseo y muerte al considerar que existen partes inconscientes (o "irracionales") y conscientes en el pensamiento de los sueños, los cuales son capaces de conectarse entre sí a partir de una determinación inscrita en el contenido latente y que es capaz de desplazarse de manera desfigurada hacia el contenido manifiesto, no obstante tienen una existencia continua. Es decir, son capaces de reemerger en el sueño como fantasmas que animan y abren una cierta vida pasada. Este desplazamiento de esa relación tiene como resultado un concepto, en la teoría del sueño, de muerte en el cual está presente un factor desiderativo ${ }^{7}$ como un elemento irreductible. 
De una cierta manera, entonces, se instala una suerte de hostilidad que se sostendría en un concepto de "racionalidad deseante" como definición del "egoísmo" propio del ser humano. En otras palabras, lo que en el pensamiento del inconsciente son la afirmación y la negación, en el deseo, son la necesidad y la satisfacción o, en otras palabras, la persecución y la huida.

De acuerdo con esta noción, allí se juegan dos cosas: la estructura de la muerte en tanto una pulsión y el paralelo existente entre deseo y rivalidad. Desde este lugar, pues, existen dos factores que es menester declarar, en primer lugar se encuentra el factor desiderativo, que es el encargado de satisfacer algún contenido latente censurado inconscientemente y en segundo lugar, se encuentra el factor de la hostilidad o enfrentamiento que sería el encargado de constatar los medios como el deseo de muerte se realiza en una situación concreta de acción, lo que provoca la paradoja de la contradicción frente al deseo mismo.

El modo de saber, entonces, si el deseo de muerte se encuentra en condiciones de superar el conflicto interno propio de la rivalidad que se produce desde la primera infancia, no es otro que el de una reflexión "racional" sobre la propia muerte y, por tal motivo, aun cuando la rivalidad pone los fines para el deseo de muerte, el componente "racional" inscribe si el deseo de muerte puede referir a un ideal regulatorio de la rivalidad. En ese sentido el deseo de muerte puede perseguir aquello que dice la censura y reprimir la hostilidad inconsciente, dando acceso al dominio del sueño para poder realizar dicho deseo.

Este complejo proceso se podría describir como la identidad entre la determinación racional de la muerte (verifica que el deseo pueda realizarse en los sueños y que éstos se ajusten a la representación de la rivalidad) y la separación (pone el fin que persigue el trabajo del sueño), es decir, aquello que Freud denomina: placer por encontrar el objeto 
perdido. Esta identidad es la decisión deliberada propiamente tal, el momento en que la posición del deseo es referida a la averiguación y búsqueda del objeto perdido y, a su vez, es verificado con un proceso reflexivo de elaboración fantasmática de dicho objeto perdido.

Si existe una decisión deliberada, entonces, se puede sostener que solo viendo al padre muerto se está en condiciones de apreciar la fatalidad de la decisión. Por eso los errores prácticos, salidos de deseos de muerte, son trágicos. Y Edipo se saca los ojos, Antígona se ahorca y Hamlet imposibilitado de cumplir la misión que el fantasma de su padre le ha conferido, debido precisamente a que el hombre al que debe matar por ocupar el lugar del padre en relación a la madre, ha materializado el deseo reprimido incestuoso de Hamlet con su madre, Freud demuestra con el mito de Edipo y las tragedias, que en el inconsciente se experimenta un agónico arrepentimiento, cuyo estado de desesperación ${ }^{8}$ es por el ejercicio contradictorio del deseo de muerte hacia el padre o la madre en tanto son experimentados como rivalidad.

Ahora bien, la interrogante insiste y persiste: ¿cómo se relaciona la muerte con el placer? Dos podrían ser las claves que nos permitan aproximarnos al asunto y concluir, de este modo, nuestra caracterización de la muerte en particular y de la estructura desiderativa en los sueños en general. El principio del placer parece hallarse al servicio de los instintos de muerte y este instinto pone en condiciones los deseos inconscientes reprimidos para que actúen de acuerdo con determinados procesos destructores y conflictivos. Por consecuencia, nos encontramos tentados a decir que, desde un punto de vista sistemático, la pulsión de muerte se des-dobla y deviene, a través de los sueños, el movimiento lógico del inconsciente, porque su modo de operar requiere también una identidad repetitiva que determina su acción.

Siguiendo las reflexiones de Lacan al respecto, es importante destacar la toma de distancia hacia Freud subrayando, no solo su refutación frente a la idea de pulsión de muerte ligada a lo biológico, sino también el acento puesto al orden dialéctico en la dimensión subjetiva

8 A este respecto es importante precisar la particularidad de esta idea, a propósito del concepto de escepticismo en cuanto vía de desesperación en el despliegue de la conciencia trabajado por Hegel y que desarrollaremos en el segundo punto. 
de la identificación que tan fundamental es para el despliegue de la agresividad. Y que solo puede darse en el marco mínimo del reconocimiento al otro, es decir, "du je est un autre" garantizándose, a través de la identificación originaria y secundaria, la rivalidad y la agresividad. Es dentro de esta dialéctica entre el Je y el autre que es posible comprender la diferencia entre dicho Je y la figura del sujeto. Ya que lo propio de la cultura es una tendencia a confundir el sujeto con el Moi, debido a que existen incidencias lingüísticas que inscriben al je con el sujeto gramatical de la primera persona. Ahora bien, estas relaciones "diferenciales" son posibilitadas, en parte, por patrones identitarios que provienen de la conciencia del Moi y que éste encarnaría el centro de todas las resistencias a la cura de los síntomas.

Ahora bien, una lectura psicoanalítica de una dialéctica que es de suya lógica/ontológica puede ser interesante si se considera el estatuto de la agresividad, en cuanto ésta responde a una ontología propiamente racional de la dialéctica inconciencia/ conciencia del Moi que internamente "lucha" agresivamente contra sí-mismo (casi como una rivalidad consigo mismo) pasando por un estado de desesperación y, por lo mismo, un estado escéptico hasta alcanzar su propio reconocimiento a una suerte de "reconciliación" en la cura de los síntomas.

[...] Un Hegel avait donné la théorie pour toujours de la fonction propre de l'agressivité dans I'ontologie humaine, semblant prophétiser la loi de fer de notre temps. C'est du conflit du Maitre et de l'Esclave qu'il déduit tout le progrès subjectif et objectif de notre histoire, faisant surgir de ces crises les synthèses que représentent les formes les plus élevées du statut de la personne en Occident, du stoïcien au chrétien et jusqu'au citoyen futur de l'Etat Universel» ${ }^{10}$

Se podría decir que el estatuto del reconocimiento, desarrollado por Lacan, es analizado por medio de la lógica dialéctica dominación/servidumbre de Hegel. Ahora bien, a partir de allí, dicho reconocimiento pasa por una relación entre el sujeto delante del maestro absoluto que, en Lacan, será la muerte, puesto que la muerte cumpliría la figura de lo absoluto que escapa a todo dominio, presentación y saber.

9 Lacan, Jacques. L'agressivité en psychanalyse en Ecrits. Du Seuil, Paris, 1966. Pág. 118.

10 Op. cit. Pág. 121. 
Para ilustrar aquello tomaremos la relación de transferencia entre el analista y el analizado, puesto que dicha correspondencia posibilita enfrentarse a la muerte. Ya que, según Lacan, el analista presentifica la muerte pero a condición de desprenderse de su lugar narcisista de su Moi, pues es la barrera de la imagen narcisista del moi que constituye todas las formas del deseo.

Si bien, Lacan proclama un pensamiento sobre el deseo de muerte, tal y como lo habría pensado Freud en los análisis anteriores sobre L'interpretation du rêve, no obstante esto, el reconocimiento del deseo de muerte tiene que ver con el desprendimiento de la imagen narcisista del Moi y las saturaciones del superyó propias a la agresividad, pues es la expresión del moi quien promueve la concepción utilitaria del individuo en la sociedad.

Una vez establecida la necesidad de un pensamiento objetivo en relación al estatuto del sueño, la rivalidad y la muerte, en tanto categorías claves para especular un pensamiento subjetivo de la agresividad, ahora se procurará mostrar que, pese a que el método de la interpretación de los sueños freudiana -en relación a los deseos, la rivalidad y la muerte- y la propia doctrina lacaniana -en correlación a la agresividad, la subjetividad y la noción de muerte ligada a la disolución del moi-fueron posiciones de pensamiento de las cuales ambos autores no han prescindido, sin embargo existen núcleos teóricos de carácter general que permanecen, a mi juicio, no solo en la convicción de cada autor por muy distantes que puedan parecer, sino además que en ciertos análisis más contemporáneos, estos núcleos cruzan otras disciplinas.

Para tal efecto se acudirá a lo que Catherine Malabou ha denominado "une rencontré manquée" y que nos daría pie para pensar una suerte de "crítica del análisis del inicio". En su libro Les nouveaux blessés, el capítulo titulado: La séparation, la mort, la chose Freud, Lacan et la rencontré manquée. Catherine Malabou examina el dominio de la pulsión de muerte como aquello que desencadena el aniquilamiento, la destrucción, finalmente la separación. La lectura que hace Malabou con respecto a este encuentro entre Lacan y Freud no es objeto de un estudio sistemático. Sin embargo puede aproximarnos a una nueva mirada frente al inconsciente en tanto lugar originario de la destrucción o aniquilamiento, en otras palabras, la muerte. 
Ahora bien, el primer estudio reagrupa cuatro apartados reunidos bajo diferentes títulos pero que, en su conjunto, giran alrededor del concepto de muerte en tanto separación consigo mismo a partir del punto de vista freudiano. Un segundo estudio gira en torno al aniquilamiento propiamente tal. Un tercer estudio estaría consagrado a Lacan mismo y sus postulados en relación al carácter indisoluble de la borradura del sujeto del inconsciente, en otras palabras, a la condición de tachadura indestructible que se registra de manera escripturaria ${ }^{11}$ en el inconsciente en cuanto inscribe la desaparición y por lo tanto, la anticipación de la muerte.

La lectura atenta de los estudios que desarrolla Malabou permite ver, no obstante su correspondencia entre Lacan y Freud, sus diferencias o más bien su aparente indiferencia. Es bien la naturaleza de esta correspondencia que hace la singularidad y la irreductible originalidad de este estudio. ¿Cuál es la dirección exegética abierta para esta correspondencia? En la primera exposición Malabou muestra, de

11 La noción de scripturaire viene de cripta y permite comprender la idea de tachadura que, si bien esta noción fue acunada por Jacques Derrida, quien interpreta el inconsciente freudiano en términos de traza, no es menor pensar que si el inconsciente tiene forma de cripta, Derrida apuntaría el hecho que existe una escritura que va ligada más a una suerte de filosofía de la traza o escritura sin conciencia. Por su parte, Jacob Rogozinski en su libro titulado: Faire part, cryptes de Derrida. [Lignes, París, 2005] El autor señalara que si bien la muerte en general, en tanto posibilidad anticipada de lo imposible, es la propia muerte, en sentido heideggeriano, entonces, la hipótesis de "hacer parte" de la muerte del otro, implicaría la propia muerte. Pues comienza un tiempo de duelo donde surge un gesto narcisista por el hecho de la angustia que provoca la muerte del otro y la posibilidad de la llegada de la muerte propia. $\mathrm{Si}$ existe un duelo de sí, imposible de disociar con la muerte del otro, entonces la propia posibilidad, la más interna, de aquello imposible vendría siempre del otro. De esta manera, la idea de Rogozinski en relación del título que nombra el libro: faire part anuncia el hecho que hay una "part" que nos convoca e involucra en cuanto una distancia, pero al mismo tiempo una proximidad con respecto de la muerte del otro y que se vería reflejado en hacer el duelo del duelo mismo en cuanto su singularidad radical. Es este duelo singularmente radical que nombra la traza y que se resiste a su borradura lo que enuncia la idea de cripta. "Une trace ineffaçable ne serait pas une trace, et c'est la possibilité de son effacement qui donne sa chance à l'écriture" [P: 11]. Ahora bien, y es esto lo que me interesa destacar, la figura de una traza singular que funciona a modo de cripta, no quiere decir que es algo fijo, sino que se repite, se altera, es decir, tiene plasticidad, lo que promueve el juego ilimitado de su sustitución y su desplazamiento, pero a condición de hacer una experiencia donde, si bien dicho juego transgrede el límite de lo deconstruible, por decirlo en términos derridianos, el juego de la borradura de la traza al mismo tiempo que desaparece, permanece. 
manera completamente rigurosa, que, según Freud, el inconsciente al no conocer ni el tiempo, ni la muerte, no obstante, se estructura de acuerdo a su condición de inmortalidad en la medida que existe, también, una tendencia a su destrucción. De suerte que no habría, según Freud y como lo señala Malabou, fenomenalidad específica del aniquilamiento, puesto que esto ocurriría a condición de una cierta amenaza de peligro interior y exterior y que sería sufrido por el Moi. En otras palabras, es el moi quien, sometido a un danger $a b o l u^{12}$, se abandona a las protecciones y las defensas arrojándose en la angustia de muerte, lo que provocaría, acaso, una destrucción psíquica de parte del moi. Así al concepto de aniquilamiento correspondería el estatuto inconsciente. [...] Comment le psychisme appréhende t-il sa propre fin? ${ }^{\text {33 }}$

Si al concepto de muerte concierne el estatuto de la aniquilación, entonces, se podría hablar de un dolor "trascendental" en la medida que el psiquismo tiene de suyo una separación con el mismo, puesto que su desaparición obedece a una suerte de dialéctica de lo en-sí de lo psíquico que deviene un para-sí en él mismo. De esta manera, entonces, la brecha que separa esos dos momentos tiene como condición la inscripción de la categoría de la mortalidad, pues constantemente se va desvaneciendo. Malabou llama a este estado el peligro "real" del corte, donde se alojaría la castración, el castigo, pero además, el nacimiento.

"Pour Freud, le rapport du psychisme à sa propre disparition est envisagé comme une séparation du psychisme d'avec lui-même. La séparation d'avec soi est le phénomène psychique de la mortalité. Pour Freud, I'anticipation de la mort est vécue comme adieu du moi à lui-même» ${ }^{14}$

El inconsciente sería una pasión lógica, un afecto conceptual que registra la propia muerte en el momento de la separación consigo mismo y que vería sus resultados en la experiencia de la conciencia del Moi. He aquí lo que declara Malabou, y que entra en juego con el rol de la angustia radical, "I'angoisse de séparation, affect de la coupure

12 MALABOU, Catherine. La séparation, la mort, la chose Freud, Lacan et la rencontre manquée. En Les nouveaux blessés: De Freud à la neurologie, penser les traumatismes contemporains. Bayard, 2007. País, Pág. 207.

13 Op. cit. Pág. 208.

14 Ibídem. 
comme tel, c'est très précisément sur de telles définitions que portera la controverse avec la neurologie 115 . Por su parte, el carácter discursivo que presenta el análisis de Malabou sobre los postulados de Freud, nos rinden cuenta de cómo es posible pensar la angustia en relación, no solo a un peligro interior, sino también a una amenaza exterior. Desde esta perspectiva, pues, la angustia sería el momento límite entre la separación y el desgarro.

Los libros de Freud sobre la angustia, a saber, la "Métapsychologie", "Inhibition, symptôme et angoisse" $\mathrm{y}$ "Le moi et le ça" que se presentan bajo una forma depurada y rítmica retoman, en efecto, los puntos esenciales de la explicación de la angustia. En tanto expresión afectiva del peligro pulsional interior y cuya revelación se manifiesta como reacción frente a una amenaza exterior, se puede advertir allí una dinámica, una plasticidad entre lo interno y lo externo, que pondría en lugar también y a partir de esta dualidad, la producción de la represión, en cuanto sería la reacción interna, pero además la reacción directa al peligro externo, en cuanto se expresaría como la "fuente" de la represión. Esta dinámica o plasticidad donde convergen lo interno y lo externo, la causa y la consecuencia, reconducirían a la destrucción del psiquismo como fenómeno de separación consigo mismo.

Se podría decir que existe una proveniencia casi ontológica del peligro, y para eso habría que disponer de un concepto "pre-constituido" que dé cuenta de dicha proveniencia. Sostengo que el peligro de separación, el cual emerge bajo tres figuras: el nacimiento, el castigo y la castración, no es otra cosa que una negatividad comprendida como ausencia de fondo, un silencio sobre su ser pulsional. Por ejemplo, siguiendo a Malabou, el castigo de la castración tiene que ver, en el fondo, con la pérdida, con la amenaza en sí, lo que conlleva el abandono y cuya consecuencia sería una ausencia.

Una pregunta esencial aparece aquí: ¿por qué toda angustia, amenaza o peligro busca refugio en la separación sin justificarse, estas tres formas, dialécticamente o dinámicamente, y sin poder determinarse ellas mismas, como un problema propio de la muerte como negación? El 
carácter no interrogado de la negatividad es sin cesar aquí reafirmado. ¿Qué tipo de separación está aquí en juego? Según Malabou, coexisten tres formas de separación. Primero, la angustia del nacimiento cuya manifestación es la separación de la madre, segundo, la angustia de separación, cuya expresión sería el castigo bajo la ordenanza de la amenaza, de parte de la madre, del abandono afectivo y finalmente, la angustia de castración que tiene de suyo la sustitución al miedo del castigo. Se puede observar allí que las tres formas de la separación se condicen entre sí y que en Freud, su mérito nos señalaría que la base de estas tres figuras de la separación responden a un estado de impotencia y, por tanto, de pérdida y exclusión de parte del Moi.

La fuente que sostiene la situación de peligro real es mucho más arcaica que el peligro pulsional, el cual aparece como la traza o el recuerdo inmemorial. De esta manera, entonces, el lugar que ocupa la represión no es sino una acción que anula, pero, al mismo tiempo provoca placer. Se podría hablar aquí de un dolor esencial, en la medida donde se va manifestando una experiencia trascendental de la separación fundacional. En otras palabras, aquella separación originaria o fundacional sería una dimensión que abordaría todo un proceso de angustia propia de cada separación particular.

¿Dónde estaría el origen de la muerte entonces? Si bien el ser humano experimenta "peligros", éstos señalan que existe un aniquilamiento que inaugura el corte o la desintegración consigo mismo y en-sí del psiquismo. Malabou justifica aquella afirmación mostrando que Freud no piensa en una representación del aniquilamiento o del concepto de muerte en cuanto origen $\mathrm{o}$, al revés, origen de alguna representación tal. ${ }^{16}$ Puesto que la muerte reside irrepresentable, la noción de aniquilamiento o desintegración que estructura el inconsciente solo es posible a partir de la experiencia de la castración en sentido fenomenológico, es decir, cuando el moi reacciona frente a la angustia de muerte a través del abandono del superyó, generando un corte que deviene destructor. En otras palabras, lo en-sí del moi que se anula y deviene un para-sí del

16 «[...] En effet, il n'y a, dans l'inconscient, aucun contenu de sens associé au concept de la mort propre.: «Ma» mort demeure irreprésentable» [... L La mort est un concept abstrait au contenu négatif, pour lequel on ne saurait trouver une correspondance inconsciente (Le moi et le ça. Op. cit, P:27) Op.cit. Pág. 214. 
super-yo que, a su vez, también se anula "representando" el momento de castración del moi en cuanto ha sido disociado de él mismo.

Ciertamente el concepto freudiano de castración se define como simple doble del otro del moi mismo. Sería una situación de extrañeza ominosa en cuanto instancia del propio moi en su interior y que va deviniendo, extrañándose a sí mismo para, de esta manera, inscribir la separación en-sí y consigo mismo. Esta repartición que desdobla al moi, testimonia una inmediatidad indeterminada cuyo destino es la anticipación desplegada del moi, que deja y saca al otro de sí mismo, disponiéndose, en este movimiento a su vez, a precederlo en la nada, en la desaparición. Así, muerte y escisión se com-ponen recíprocamente en tanto que ambos concuerdan en su horizonte de desaparición. Sería la escisión como la figura del doble que se va desplegando en cuanto el aspecto inmortal del moi y que se expresaría, en sentido lacaniano, como el doble repetido fantasmático, es decir, como la muerte. Pero en sentido hegeliano, como la negatividad, en tanto espacio de la diferencia, en el movimiento dialéctico interno a la unidad contradictoria de la identidad y la diferencia y que posibilita su surgir y desaparecer.

En efecto, la efectividad de este proceso sería la significación y comprensión de una diferencia en la identidad del propio moi. En efecto sería un desdoblamiento diferencial, referencial y repetitivo que tomaría forma como una alteridad lógica en la estructura psíquica del inconsciente. La muerte, expresada en la angustia de castración, está destinada a faltarse ella misma, es decir, en defecto esencial del sí mismo y su constante amenaza de separar el sí de él-mismo, la muerte podría ser una "negatividad" dialéctica que desdobla e inscribe la escisión. De esta manera, entonces, si la separación es una suerte de ir desdoblándose, desplegándose el moi consigo mismo, se podría considerar que se da una fundamental ilegalidad en-sí de la muerte que anticipa, en su proyectar reflexivo, la disociación mortífera de símisma y consigo misma. Y que negándose en este desdoblar registra el origen de la especulación o "reflexión" donde el moi se toma él mismo en su devenir otro de sí, es decir, un para-sí, como objeto.

"[...] c'est la coupure, son fantasme ou son anticipation qui ouvrent à la psyché l'horizon du rapport qu'elle entretient avec elle-même, la façon dont elle peut se voir mourir en se 
dédoublant. La séparation mortifère d'avec soi est l'origine même de la spéculation ou de la réflexion par où le moi se prend lui-même pour objet» ${ }^{17}$

En la medida donde se da un proceso de negarse el moi de él mismo, a través del desdoblamiento mortal, y este negativo no es interrogado en cuanto a su origen, reside en él mismo una "ocultación", a saber, la obliteración ontológica de su dimensión fenomenal. He ahí el acontecimiento que afecta la estructura de antelación que ha sido transformada por la posibilidad originaria de la despedida a sí mismo del moi. Ahora bien, si la muerte es pensada dialécticamente, es decir a partir de lo otro de sí, en cuanto se desdobla, entonces la muerte aparece siempre como fantasma de la separación, y como una muerte "sin catástrofe" no obstante considerada, también, como una negatividad, en cuanto, desgarramiento y separación. En consecuencia, todo se invierte y deviene, sería la espera del duelo de sí o la espera como duelo de sí, yacería, entonces desde ahí, la negatividad en tanto maestro absoluto que resiste a la muerte, sin embargo, la dilucida como indestructible.

El carácter indestructible del aniquilamiento, es el punto central del acontecimiento de la anticipación de la separación, es decir, el hecho que inscribe y posibilita la estructura de borradura del sujeto es su anticipación al corte. Sin embargo, dicha tachadura es imborrable por ser indestructible. ${ }^{18}$ Así pues, con una tal borradura imborrable la muerte no podría adjudicarse una catástrofe posible, pues sería lo indestructible de la destrucción.

Entonces, cabe preguntarse: ¿cuál es la relación del inconsciente con su destructibilidad? Según Malabou, Lacan precisa aun más esta relación. Puesto que, para Lacan, la estructura de la separación es entre el moi y el sujeto, luego en esta separación, Lacan inscribe la alteridad que, a mi juicio, sería la categoría de diferencia hegeliana desarrollada en su libro "La Science de la Logique", deuxième livre. Logique objective. Dicha diferencia, sería la falta en-sí del moi que no solo y al mismo tiempo marca la rúbrica de la finitud que formaría la estructura de

18 A este respecto ver Jacques Lacan, Le Séminaire VII, L'éthique de la psychanalyse, Du Seuil, Paris, 1986, Pág. 225. 
anticipación y espera de la muerte, sino también, devendría como la negación de la falta en-sí que se anticipa al sujeto para-sí mismo en su puro reconocimiento en cuanto lo otro absoluto.

Es en esa estructura, en el hiato o alteridad donde acontece lo "Real" o el "entre-decir" que no puede ser-dicho ni simbolizable. Puesto que dicha disposición obedece a un orden que, en su diferencia, se desdobla en su negativo, formando una frontera que marca el suceder, el surgir de acontecimientos que devienen imposibles de llegar o aparecer y cuya significación no es sino la negación del acontecimiento. Un conjunto de no-advenimiento en tanto punto de fuga de lo Real que espera.

Se trata menos, para Malabou, haciendo la lectura lacaniana, de volver a poner en cuestión el parentesco estructural entre inconsciente y destrucción que de develar la imposibilidad de lo real por su régimen de fuga, no obstante, posibilidad de unidad separada en un reencuentro hacia el lugar de lo inseparable.

"Il faut alors penser l'inconscient comme cette coïncidence de la rencontre et du point de fuite, possibilité conjuguée des événements qui arrivent et de ceux qui sont au-delà de tout avoir lieu.[...] le Réel se tienne au-delà du symbolique. Le Réel-ou ce qui est proprement traumatisant dans le trauma-ne correspond à aucun symbole, c'est-à-dire à aucune structure d'unité fragmentée, à aucune «soudure». Le Réel est l'inséparable. Sans distance, sans horizon, sans fissure ni manque ${ }^{19}$

Las consideraciones preliminares del texto de Malabou retoman la idea de una negación del horizonte de permanencia psíquico, cuyo estatuto es él mismo una advertencia de destrucción real. Puesto que lo que se ve amenazado, finalmente, es el desastre del horizonte mismo. Horizonte de la separación.

Ahora bien, el desastre o la destrucción no es posible sino a condición de un resto, de una ruina. Desde esta perspectiva, entonces, Lacan inscribirá una "sutura" que no es sino aquello que da el nombre de

19 MALABOU, Catherine. Les nouveaux blessés: de Freud à la neurologie, penser les traumatismes contemporains. Bayard, 2007. Pág. 225. 
cosa [Ding]. Esta "cosa", que sería el otro absoluto del sujeto, un agujero o vacío; el Otro prehistórico o, según Malabou, el resto, es una parte fundadora de la estructura inconsciente y, al mismo tiempo, él no es más que un componente interno del sistema inconsciente. Dirá Malabou que dicha figura designada como "cosa" es aquello de Real que se resiste al significante y, no obstante, lo goza.

Esta doble situación, fundante e interna, permite comprender la idea de espera en cuanto es la "falta" que funda y es interna a un proceso que otorga el movimiento de experiencia del inconsciente, en la medida donde la "cosa" concede el horizonte de un rencuentro faltado entre lo Real y la falta misma. Recordemos, a este respecto, el capítulo consagrado a la Tuchè et automaton del Seminario XI titulado Les quatre Concepts fondamentaux de la psychanalyse. En ese momento allí, Lacan elabora las nociones de azar y necesidad, como incluso, las concepciones de reencuentro de lo Real. ${ }^{20}$

20 A este respecto ver el capítulo titulado «Tuchè et automaton». Del Séminaire XI: Les quatre concepts fondamentaux de la psychanalyse». En ese capítulo Lacan elabora las nociones de azar y necesidad, del reencuentro de lo Real en relación a la Tuché y l'automaton. Ahí Lacan propone hacer un vínculo entre estas cuatro nociones proponiendo que existe une ligazón entre azar, Real y tuché. Primero que todo la noción tuché dice relación con lo Real, puesto que lo Real es un encuentro con alguna cosa que se oculta y escapa, es decir, que desaparece. Sin embargo este encuentro se determina por azar y es por esto que lo Real adquiere la figura de lo inesperado e imprevisible, casi la figura de un acontecimiento que se caracteriza por ser indeterminado. Ahora bien, si la función de lo Real tiene que ver con alguna cosa que es huidiza y que se escapa, es porque lo Real es un registro que no es reproducible, sino aun, contingente, donde dicho encuentro jamás se realiza, es por esta idea que Lacan habla de un encuentro faltado, «qu'essentiellement elle est la rencontre manquée» [Pág. 54]. Por consecuencia, lo Real o específicamente, la tuché yace en la falta del encuentro, por su misma condición de azaroso. De suerte que el horizonte de fuerza de aquello contingente que nombra la tuché es precisamente su condición de imposible, debido justamente a su régimen de encuentro faltado, de un encuentro imposible. Por su parte, la relación entre azar, Real y tuché permite pensar los acontecimientos del pensamiento y particularmente, el estatuto racional del inconsciente, a partir de ciertos accidentes puros que son de carácter inasimilable. Sin embargo, reaparecen durante una «espera» que insiste y que tiene la forma de ruptura o corte, pero también, con una insistencia que va adquiriendo la forma de repetición. Por consiguiente, este aspecto repetitivo es lo que Lacan va a llamar el automaton. Brevemente, el automaton quiere decir el retorno a un encuentro con un acontecimiento contingente que produce cierta dislocación, una fractura o escisión en cuanto un acontecimiento inesperado. Pues "Ce qui se répète, en effet, est toujours quelque chose qui se produit (...) comme au hasard» [Pag: 54]. En otras palabras, se puede decir que la repetición cuyo carácter 
A partir de ese momento de unión entre azar y necesidad, reencuentro y Real, la experiencia del inconsciente nace del régimen de operación del proceso propio de dicha unión, donde los accidentes puros (tuchè) y los sucesos vividos o fantasmáticos (automaton), o más bien, los acontecimientos y no-acontecimientos son ellos mismos los que inscriben el propio concepto significante en la lógica del inconsciente. Esto revelaría la prueba ontológica inconsciente. Este no es experiencia de objeto/cosa, pues la cosa daría cuenta de lo Real posible e imposible que rinde operable la tuchè (azar) sino que su experiencia es sobre el origen mismo del rencuentro faltado. En otras palabras, el no-acontecimiento (tuchè) aquello que no tiene significación, provoca el acontecimiento (automaton) y la "cosa" se produce al momento preciso de la unión entre la falta de reencuentro y el reencuentro. En ese punto de contradicción emerge la "cosa".

es automático, busca la confluencia con este acontecimiento Real y contingente, no obstante, no lo encuentra jamás. En esas condiciones, pues, el automaton seria lo determinado con el primer encuentro faltado con lo Real. Esto deja entrever que la función del automaton estaría del lado de la cadena significante, ya que nombra su estructura en cuyo rendimiento estaría el movimiento que se repite. Sin embargo, contiene una negatividad, una «falla» que deja escapar lo irrepresentable, por eso queda inscrito como innombrable, inter-dit o no-dicho propio a lo indeterminado. Por su parte y siguiendo a Malabou, si la tuché es lo que adviene por azar, es decir, bajo la idea de un accidente, entonces el automaton «désigne littéralement «ce qui se produit de soi-même», ce qui marche tout seul et se répète selon une stricte nécessité mécanique» [Les nouveaux blessés: de Freud à la neurologie, penser les traumatismes contemporains», chapitre: «La séparation, la mort, la chose Freud, Lacan et la rencontre manquée». Pág. 227]. De hecho se puede ver una articulación entre la necesidad y la contingencia o entre la sustancia y el accidente en la medida también, de observar ahí, la posibilidad de conexión con el pensamiento de Hegel en lo que concierne al método dialectico y la lógica que mueve dicha actividad. Puesto que lo que caracteriza el régimen de esos acontecimientos es la necesidad y la contingencia o, más bien, la esencia y el accidente, pensando desde Hegel, se podría sostener que el sentido que se juega ahí, es a través de la dialéctica como la organización del encadenamiento de los significantes, bajo una lógica estructuralmente necesaria. Siendo el régimen de esta necesidad, la identidad especulativa entre significantes finitos que cada uno legitima, es decir, que expresan un principio racional donde es posible manifestar lo incondicionado, a saber, lo Real. Ya que se sabe que en la economía significante, que se caracteriza por el automaton y la tuché, es decir, se caracteriza por el encuentro faltado, este encuentro faltado, a su vez, se "pierde". Lo que connota una unidad contradictoria e inmediata entre encuentro y pérdida, entre lo que determina el encuentro y lo que se pierde en lo incondicionado, y que se traduciría en una relación de sustancialidad entre el tuché y l'automaton, pero, además, donde la "negación/negatividad que se manifiesta ahí, es en relación al régimen de la borradura en cuanto traza que marca el significante, lo que permite dilucidar aquello en la base del movimiento de la economía significante. 
"La tuchè révèle donc comme sa fin propre l'automatisme de répétition qui, pour Lacan, est commémoration signifiante. C'est dans le rêve seulement que peut se faire cette rencontre vraiment unique. Seul un rite, un acte toujours répété, peut commémorer cette rencontre immémoriale». ${ }^{21}$

De este hecho, pues, se podría decir que la "objetividad" del inconsciente se funda y se determina a partir de la función originaria del espacio de espera y desplazamiento mismo, en tanto horizonte de separación consigo mismo de la psique. De suerte que la prueba del corte, o castración queda estructuralmente como un resto, como un lugar indestructible de la destrucción. De esta manera, entonces, la función "unificante" e incluso imborrable de la separación, que no es otra cosa que aquello que constituye la borradura en cuanto traza del significante, sería la significación ontológica en la medida que manifiesta el dolor trascendental expresado y exteriorizado en la conciencia del moi.

"La nature du signifiant est justement de s'efforcer à effacer une trace. Et plus on cherche à l'effacer, pour retrouver la trace, plus la trace insiste comme signifiant».22

De esta manera, la experiencia del trabajo del dolor trascendental no es otra cosa que la separación, y cuya significación será su propia borradura, es decir, que dicha separación no se borra jamás.

En conclusión, aquel dolor y aquel trabajo, a mi juicio, deben ser referidos a la definición hegeliana de experiencia de la conciencia como "camino de duda y desesperación". Se trata ahí del sufrimiento que experimenta la conciencia del moi en la auto-producción de su esencia inconsciente, a saber, la traza borrada del devenir significante. La cual implica cada vez una pérdida: la pérdida de lo que ella tenía de esencial negativo. En efecto, se sabe que Hegel caracteriza esta pérdida como factor de desesperación, o aun, de muerte en cuanto, para Hegel, la muerte es la negatividad absoluta. He aquí la figura del escepticismo. Esto provocaría el desgarramiento en-sí y para-sí más

21 MALABOU, Catherine. Les nouveaux blessés: de Freud à la neurologie, penser les traumatismes contemporains. Bayard, Paris, 2007. Pág. 232.

22 Op. cit. Pág. 233. 
allá de ella misma. En consecuencia, en esta muerte constante, la conciencia y con ella el inconsciente, hacen el sacrificio de su muerte a fin de ganar, a partir de dicho sacrificio, su reconocimiento de sí mismas. Se trataría aquí de lo otro de sí en-sí.

\section{Goce y escepticismo: Hegel en Lacan, un encuentro re-inventado.}

Caracterizado como un intento de gran proyección consistente en pensar el "secreto" de la conexión entre lo finito e infinito, que no es solo la contradicción entre vida y muerte sino también le organización inconsciente de esa contradicción pulsional, cabría señalar, pues, la conexión y vínculo con el pensamiento hegeliano al respecto. Puesto que la coherencia y validación de argumentos en relación a dicha conexión podrían arrojar unas primeras tentativas de lectura e interpretación.

Si bien existen problemas de método entre el psicoanálisis, particularmente lacaniano, y la obra de Hegel, no es menor pensar que el propósito aquí y a lo largo de la investigación es la de apoyar una tesis importante de mi criterio de lectura: la importancia central de la articulación, no solo entre lógica y fenomenología y/o lógica y filosofía del espíritu, sino además, la pertinencia de dicha articulación con el pensamiento psicoanalítico de Lacan.

En cierto modo, la pertinencia de una posible articulación solo puede darse si tomamos la categoría de "estructura". ¿Cuáles serían los elementos esenciales de la formación del concepto de estructura? Es decir, y siguiendo las palabras de François Balmes, se trataría de poner en marcha una interrogación sobre les conditiones théoriques de I'apparition de ce concept dans la psychanalyse chez Lacan. ${ }^{23}$ Si la estructura, en Lacan, define o podría especificar un sistema de pensamiento que acordaría ciertas facultades a la relación del sujeto y la verdad, esto conllevaría, así, la emergencia de una forma de argumentación que

23 BALMES, François. Structure, logique, aliénation: Recherches en psychanalyse. Editions érès. Scripta Collection de I'Ecole de psychanalyse Sigmund Freud, Paris, 2011. Pág. 11. 
centraría sus preocupaciones en despejar los obstáculos [históricos] a la operación propia de la actualidad de la estructura, a saber, el hecho de volver a poner en causa una refundación de la comprensión de los conceptos inscritos ahí y que nombrarían, de una parte, la estructura como "sistema significante" $y$, de otra parte, el "significante" como elemento de la estructura, ya que, desde esta perspectiva, ellos mismos van adquiriendo su (re) significación en el movimiento general de dicha argumentación.

Ahora bien, a partir de la categoría de estructura, localizaremos el problema de la muerte en dos figuras fundamentales: por una parte, al desplazamiento como despliegue hacia el origen fundador de la relación del sujeto y el Autre; y cuyo primado es precisamente del significante, en cuanto entraña una negativación de todos sus términos que lo conciernen, es decir, de todo lo que podría comportar una cierta ontología de la repetición y la diferencia con respecto al ser, la presencia y la disolución. Por otra parte, al desenvolvimiento lógico en Hegel cuyo movimiento va produciendo y conteniendo el escepticismo en cuanto escritura de la muerte, para, posteriormente, situarlo al respecto dialéctico de lo lógico que existe en el inconsciente "estructurado", no ya como lenguaje, sino que en tanto es un sistema de lugares y co-relaciones donde el escepticismo sería aquello que organizaría dicho inconsciente.

En otras palabras, se trataría de pensar el escepticismo como la estructura inconsciente en la medida donde es posible revelar el poder/ im-poder de la muerte, es decir, de este "Otro" negativo imposible de simbolizar, en su disimulación más profunda. Brevemente, se trataría de conferir una base escéptica a la muerte en el sentido lógico del término. Sería, en sentido hegeliano, la proposición que da cuenta de la "estructura" de lo absoluto, a saber, la identidad de la identidad y la no-identidad. Como también daría cuenta, en sentido lacaniano, del primado del significante, en cuanto que él es producto de una repetición y que reposaría sobre una diferencia y sobre una no-identidad consigo misma. Es en ese lugar de la no-identidad donde se inscribe la fractura inconsciente, donde aparece un resto no simbolizable adscrito al registro de lo Real. Entonces, si al interior de la subjetividad persiste un resto que define una suerte de exclusión, se podría decir que ahí mismo, se da un lugar de "re-conocimiento" de dicha exclusión cons- 
tituyente, como también y a la vez se produce un "des-conocimiento" ante dicho espacio diferenciado e inter-dit [inaccesible].

Desde este punto de vista, pues, si en la estructura del inconsciente no hay presencia a sí misma, puesto que no hay Otro del Otro, entonces lo que causa la estructura es una pérdida, una disolución [escéptica] que al mismo tiempo que produce el significante, inscribe algún lugar originario que es innombrable. A saber, la traza de la muerte. Convocar un origen es nombrar la estructura y, por lo mismo, es el ser de la falta en el sentido de la tachadura del Autre, lo que demuestra el hecho de hacer prevalecer la diferencia por sobre la identidad, la pérdida por sobre la presencia. Tal contraposición comportaría una negativacion que no tiene por función derogar sino que, a partir de su operación de "anular", contiene y mantiene la traza en la borradura de la misma. La determinación exhaustiva de esta operación sería la insistencia del origen del significante, cuya persistencia pone en relación dialéctica la traza (o tachadura) y su borradura. He aquí el ejercicio de la operación escéptica en sentido hegeliano.

Al respecto de esto se podría constatar, por lo tanto, que el extravío o abandono es de suyo un origen $y$, a su vez, lo originario es aquello perdido u olvidado no obstante permanece. Lo que dejaría entrever la descomposición de aquellas contraposiciones inaugurales que inscriben el inicio del discurso en el goce (jouissance). Discurso que nombra el efecto del significante, a saber, el sujeto nacido de la disolución o más específicamente de su abolición. [l'Aufhebung].

Ahora bien, si nos detenemos en el tema del goce desarrollado por Lacan, se puede observar las diferencias que establece con el placer. Primero que todo, si bien la estructura se identifica con un origen y cuya negativaciôn inscribiría un agujero, un "defecto" o una falta, por lo tanto, podríamos retener la idea que aquella negativación no sería sino una falta en tanto un silencio que está entre-dicho [interdit/ prohibido]. Desde esta perspectiva, pues, se trataría allí de poder instaurar la distinción entre goce y placer, en el sentido de que dicha distinción no se agota en la satisfacción mezclada con la pérdida, el duelo, la tensión o el dolor en sí mismo, sino que la conceptualización del goce permite comprender que el deseo mismo estaría constituido por la relación con la palabra. 
De ésta manera, el goce concierne a un deseo que es, precisamente inconsciente, y que su correspondencia original es con la estructura que relaciona los significantes con el objeto de la jouissance, y cuya concatenación de la cadena significante otorgaría la tachadura en tanto un goce interdicto. Es decir, entre-dicho en el sentido que sería el lugar del Autre que no es representable y que estaría en un espacio "entre" de desplazamiento, lo que rendiría cuenta del estatuto de la diferencia en la cadena significante. En consecuencia, el Autre, sería el lugar del goce interdit (entre-dicho) en cuanto éste habita y contiene el lugar de los significantes que estarían marcados por una falta estructural. He ahí la idea de incompletud de la textura de la estructura.

¿Podrá todo aquello, acaso, alcanzar una definición que gire alrededor de una suerte de experiencia scripturaire que dé cuenta de una estructura que contenga, de suyo, un desastre de la nominación? ¿Cuáles serían sus condiciones de posibilidad? Se trataría aquí de una pasión del pensamiento de lo negativo que se especifica a través del goce, en tanto dialéctica de la repetición de la pérdida y la aparición del objeto deseado. Ciertamente ahí se expresa un lenguaje que se repite en su diferencia, en su negación del significante en tanto textura que teje la materia de este goce, a saber, en la dialéctica entre repetición de la pérdida y su retorno. De hecho, se podría señalar que lo propio de la estructura es la mediación de la negatividad cuya "regla" no es sino de distancia y destrucción del objeto por medio de su muerte.

Ahora bien, si el goce es definido por su relación con el significante de la falta en el Autre-que no es otra cosa que la tachadura del sujeto-, allí el sujeto mismo se inscribiría como un "lugar" y su experiencia escripturaire marcaría el puro No-Ser. Es, en efecto, en este cruce entre sujeto y lugar donde el concepto de incompletud liga al hecho que el lenguaje de la muerte legitima una proposición que garantiza la estructura de manera respectiva y cuyo "tejido" es su textura relacional. A la luz de Lacan, el inconsciente estaría más próximo a un fundamento cuyo contenido es la síntesis ruptura/unión ontológica entre lenguaje y sujeto. Lo que demostraría, así, que el goce, intrincado en este tipo de lenguaje, estaría marcado por una falta o ruptura que signa el hecho de que lo constituyente del goce mismo no es otra cosa que la estructura de un lenguaje, cuya proposición allí, marcaría la figura del ser-hablante [parlêtre]. De esta manera para 
el ser-hablante, la garantía del enunciado proposicional no sería otra cosa que la enunciación: no hay Otro del Otro.

Por su parte, si constituimos la articulación con aquello que dice Hegel en relación a la proposición escéptica y cuyo movimiento cifraría, en autonomía, lo unitario como contradicción, se podría constatar que - a designio de la proposición sobre la identidad de la identidad y la no-identidad- es el acto de la re-flexión quien "separa" o escinde lo que es uno en la identidad absoluta y se expresa en dos proposiciones: en una la identidad, en la otra la escisión, la síntesis y la antítesis separadas. De este modo si nos quedamos en el nivel del entendimiento consciente, éste enuncia como primera proposición, la identidad como: $\mathrm{A}=\mathrm{A}$ (o lo que sería lo mismo en sentido lacaniano: $\mathrm{S} 1=\mathrm{S} 2$ como efecto de enunciación) que es lo mismo que decir: lo uno es lo uno en tanto expresa la identidad del pensar de la consciencia del Yo y que no sería el pensar de lo absoluto de la razón (de la lógica inconsciente). En cambio la segunda proposición, $-A=A$ o $A=B$ (lo uno es lo no-uno), expresaría la no-identidad, es decir, aquello que el pensar (inconsciente) excluye al considerarlo como un "no-pensar" y que podría ser el lugar "interdit" [entre-dicho] del goce, su ex - pulsión. En consecuencia, ambas proposiciones estarían determinadas por aquello que excluyen [que se podría advertir no solo en el movimiento de la lógica significante, sino también al respecto de lo Real como resto excluyente y en estado de excepción].

De hecho, así como las figuras de la conciencia, en la Phenomenologie de l'Esprit devienen a partir de su inversión o -en la consideración de los momentos del devenir del espíritu-como predicados del sujeto, del mismo modo la proposición de la diferencia no indica meramente la desigualdad entre $\mathrm{A}$ y $-\mathrm{A}$ como si ambos fueran elementos abstractos (tampoco entre B, C, D, E... como si estos fueran conceptos/significantes aislados que vienen a ser unificados, asignados a un sujeto extrínsecamente por la síntesis judicativa), sino que es una diferencia relacionada o respectiva, cuya extensión adquiere y requiere intención, unidad (en la cadena significante).

Ahora bien, esta respectividad de las dos proposiciones (la identidad y la diferencia) se encuentra, para Hegel, expresada en un tercer principio, al que denomina "principio de contradicción": "poner A a la vez 
como algo puesto y no-puesto es ya la síntesis del primer principio y del segundo" (Science de la Logique: Dif 41). Debido a que $A=A$ solo puede explicarse en referencia a lo que niega. Es aquello negado $(A=B)$ lo que se revela como principio de razón de $\mathrm{A}=\mathrm{A}$. Por tal motivo, la primera proposición pone a A como puesto (como identidad puesta, excluida la diferencia), en cambio la segunda pone a A como no-puesto, pues lo puesto es $A=B$ (la diferencia puesta, excluida la identidad) que es aquello que da razón de $A$.

De esta manera ambos aspectos, el poner y no-poner de A, son parte de un mismo movimiento reflexivo pues ya Hegel, en la Science de la Logique, particularmente, en la Doctrine de l'essence, analiza la reflexión posante, externa o exterior y la reflexión determinante (la síntesis absoluta). Por eso Hegel expresa que "ambos son, en cuanto principios puestos para sí, de igual validez" (Dif: 41). Esto implica que la unidad se encuentra "ya" presente en el movimiento de exclusión-determinación recíproca, motivo por el cual el principio de contradicción (la razón hegeliana) no es una suerte de totalitarismo reflexivo que viene a engullir dos elementos heterogéneos, sino que la identidad especulativa se da "ya", de forma supuesta, en cada proposición unilateral, que al suponer lo que excluye más bien afirma su necesidad. Así el tercer principio sería la "tematización" de la interacción de los dos primeros, un movimiento de comprensión o autoconciencia.

En consecuencia, el principio de contradicción viene, ciertamente, a indicar cierto nivel de reconocimiento de tal respectividad y no a imponer un orden homogéneo; y por ello dice Hegel que ambas proposiciones "son" principios de contradicción en un sentido inverso, indicando que la contradicción es tan necesaria como la no-contradicción. En síntesis, la identidad de la identidad y la no-identidad se centra inmediatamente -judicativamente-y de manera cifrada, en la antinomia de toda proposición especulativa.

¿No es acaso posible pensar que, a partir del análisis del principio de contradicción hegeliana y su antinomia de la proposición especulativa, el estatuto del goce y el sujeto como lugar podrían enmarcarse en un movimiento que desemboca en una unidad de exclusión/ determinación recíproca en la medida que si existe un "entre-dicho" prohibido e innombrable que no da "lugar", no obstante, legitima 
un lugar a través de la tachadura como huella escripturaire? ¿Revelaría esto, efectivamente, aquello negado como su principio de razón? Ya que si existe una identidad del significante y "entre" significantes que, simultáneamente, se niegan y "excluyen" en su diferencia, ¿no estamos apelando allí a un principio de contradicción que se sostiene por un goce que deviene en-sí escéptico, pues diluye en su repetición?

Es aquí donde se daría la ocasión de profundizar el diálogo entre el escepticismo, la muerte, la estructura y el goce. Puesto que sus diferencias y al mismo tiempo "unión" sintética, permitirían alcanzar una suerte de "experiencia scripturaire" en el programa lógico del inconsciente para, de una cierta forma, revelar en qué una cierta relación dialéctica del decir y el entre-decir [interdit] -en la escritura que estructura escépticamente el inconsciente- se instaura para, de esta manera, atenuar e incluso "suprimir" todas las prerrogativas del Yo.

Insistir en esta perspectiva sobre la fuerza motriz de la negación, que inscribe dichas relaciones, como manera de explotar y de abrir los límites del ser singular del significante a su sacrificio, permitirá indicar la vía por la cual fue posible la relación anticipada del sujeto con respecto a su propia realización, en el sentido de sujeción/rechazo de sí mismo en la construcción fantasmática del Yo. Lo que ha provocado, en el interior del sujeto, una suerte de extrañeza de sí, que daría testimonio de la fisura y desgarro original como experiencia escéptica de la muerte. Así, consagrando -con el goce, el escepticismo, el significante y la estructura- el lugar central de nuestro estudio a la muerte, se trataría de rendir cuenta de las condiciones de posibilidad de aquello irrepresentable. Y que tendría la función de abrir el inconsciente para penetrar en sus interrupciones, distancias y en la falta. En definitiva en aquello imposible, como modalidad de aproximación a la alteridad y diferencia en cuanto categorías dialécticas de la negación.

Ahora bien, estas distancias e interrupciones serán lo que para el lenguaje de la muerte demostrarán mejor la necesidad de un re-decir, es decir, de la repetición. En efecto, si se sitúa el entre-decir como consecuencia de la inaccesibilidad del Autre y de un sentido único de acceso, la diferencia -consistente en no devolver al Autre a lo mismose revela plenamente mediante la repetición. Será entonces cuestión de mostrar en qué la repetición, como "estructura de goce" de la 
estructura, expresa una experiencia donde la diferencia, la identidad y la alteridad priman, en cuanto son determinaciones escépticas de la estructura misma en el inconsciente. En un primer enfoque, se podría decir que existe un discurso tanático y que en sus base aparece una cierta imposibilidad de abordar la muerte como posibilidad, puesto que ella es lo inabordable por excelencia, lo inaccesible que ratifica la paradoja del impoder. La experiencia escriptural de una forma de negativación, pues, que subsiste como un residuo irreductible, no puede sino que cruzar este límite entre el poder y el impoder, entre lo posible y lo imposible para revelar su gesto específicamente escéptico y por lo mismo, transgresivo.

A partir de este enfoque se podría constatar que la formalización que establece Lacan en relación a aquella transgresión, como superación escéptica de la escisión irreductible que se escapa, y que opera a través de una necesidad lógica, no es sino a través de la irrupción de un elemento en el fondo "irracional" donde si un S1(significante 1) asocia un S2 (significante 2), mientras que un S3 es asociado a un S4, este efecto retroactivo del movimiento significante, permite el surgimiento -en esa necesaria lógica de relación- de un significantemaestro, sin significado; en otras palabras, un significante puro cuya materialidad devendría el resto o pérdida contingente de lo Real. Sería la encarnación del puro momento particular del residuo significante, no obstante, absolutamente necesario y racional para lograr la efectividad conceptual de la estructura del inconsciente.

Insistiendo en esto, la necesidad lógica será aquella de un significantepuro singular que promueve en el cambio que anticipa, en la cadena significante del inconsciente, la construcción y aparición de otro significante. No obstante, aquel significante-uno, si bien va transformando la serie significante dialécticamente, creando las condiciones para que lo "necesario" nazca de lo contingente, la unidad dialéctica del azar y la necesidad en la estructura inconsciente, consistiría en que el surgimiento de S1 (significante-puro), el gesto que lo hace nacer, es en él-mismo radicalmente contingente, es decir, su necesidad depende ella-misma de su contingencia, contingencia que es en-sí misma lo escépticamente radical. He aquí la especificidad negativa de una repetición estructural del significante y que revelaría la infinitud escéptica de la muerte. 
Ahora bien, si se da una infinitud escéptica de la muerte expresada por un constante re-decir como repetición, también se da una finitud del pensar y la autoconsciencia, cuyo límite es el entendimiento. De hecho esta distancia entre finitud e infinitud permitirá el surgimiento de una contraposición que va a testimoniar lo múltiple o diferente al interior de la estructura inconsciente, como la unidad o unificación propia del elemento significante y cuya expresión se verá reflejada, en sentido lacaniano, en una subversión del sujeto: "je est un autre", en cuanto ambos (je et autre) definen la infinita pluralidad que representaría la diferencia y la identidad como modos de ser del Ser Uno del sujeto y que se hallan, sin embargo, contrapuestos e inscritos como el fundamento originario perdido.

En efecto, en Ecrits, el capítulo titulado Subversion du sujet et dialectique $d u$ désir dans l'inconscient freudien, Lacan se apoyará en la dialéctica hegeliana para dar cuenta de la subversión del sujeto, como lo otro de sí. Sobre este aspecto, entonces, Lacan señalará que la función del sujeto, tal y como lo ha instaurado Freud, se alejaría de la definición unitaria del sujeto del conocimiento, que ha otorgado el cuadro académico, para aproximarse a una suerte de descentramiento subjetivo cuya vía despersonalizante inscribiría, a mi juicio, la experiencia scripturaire de la muerte que acepta, sin traicionar la exigencia tanática, afrontar el no-saber y lo desconocido que le son afiliados, es decir, dicho fundamento perdido expuesto más arriba.

Es en esta perspectiva que podría ser comprendido, desde el punto de vista de Lacan y lo que expresa en el texto sobre subversión du sujet, un orden lógico en el sentido de la exigencia de una interpelación al inconsciente mismo que permita reconocer en él una voz interrogativa que lleve hacia un recorrido argumentativo que constantemente y simultáneamente se afirma como la refutación, a saber, como el recorrido escéptico que tiene de suyo la contraposición. Gracias a este enfoque es que Lacan pone en cuestión la frontera entre el saber y la verdad.

En fin de cuentas cabe preguntarse, ¿cómo es posible volver al significante-puro, allí donde sus modos de ser han sido separados y fijados por la "reflexión" del nivel del entendimiento finito y consciente del Yo, la cual, la reflexión misma, siendo parte del movimiento que 
estructura la lógica/escéptica del significante, lo limita a través de la contraposición y fijación de sus modos de ser? Lacan afirmará, desde la Phenomenologie de l'esprit de Hegel, la relación entre verdad, saber e ignorancia. Si en Hegel, según Lacan, la verdad es reabsorción y, de esta manera, asimilación constante en el devenir del saber hacia la realización de su verdad, este camino sería el modo de ser de la verdad en esto que tiene de más perturbante.

Ciertamente, aquello que perturba el despliegue de la verdad está contenido en ella misma, es decir, el momento que genera dicha perturbación no es sino aquello que falta al cumplimiento de la verdad y que el saber no logra percibirlo ni conocerlo debido a su recorrido de desesperación. Entonces, si el estatuto de la verdad es aquello del cual el saber no logra su cumplimiento, la verdad del saber es su ignorancia. Es este encuentro dialéctico que puede ser pensado, a partir de la interrogación establecida al inconsciente sobre su recorrido argumentativo para llegar a su verdad, y cuya voz interrogativa sería precisamente el decir de la muerte que se mantiene al nivel del nosaber. El inconsciente, entonces, en tanto que experiencia scripturaire, interroga el decir y se interroga como un decir, puesto que cuestiona el lenguaje (en sentido de la lingüística) y su nominación. Se podría decir que en el inconsciente, el tipo de sujeto que se concibe aparece en el momento donde el sujeto deviene él mismo una interrogación. Esta pregunta que se le puede decir "esencial" afirma la dislocación y plasticidad que opera el decir scripturaire al respecto de lo dicho.

Desde esta perspectiva, dentro de la construcción conceptual de la estructura, en Lacan, la definición de un je como significante indicaría el modo de hablar del sujeto del enunciado que, a su vez, designaría el sujeto de la enunciación, no obstante un sujeto de la enunciación que no significa nada, es decir, el je significante se expresa implícitamente en el sujeto de la enunciación y asignaría, dentro de su estatuto tácito, una falta en el enunciado. En efecto, se constatará con esto que Lacan confiere -en el significante- un sujeto de la enunciación que es negado, es decir es lo no dicho, lo que demostraría su distancia con respecto de la lingüística y un acercamiento, a mi juicio, a la ontología.

Esta relación entre la enunciación y el enunciado dentro del cual permanece y aparece el sujeto de la enunciación, instalaría la pregunta: 
¿quién habla en el inconsciente? Evidentemente esto demuestra una ignorancia en el sentido que "ça" que habla no viene sino de un lugar inter-dit que no se sabe cuándo habla y que obedecería al corte o escisión que se manifestaría en el discurso. No obstante, seria la barra entre el significante y el significado que se alojaría en la cadena significante, lo que definiría la estructura del sujeto como discontinuidad en lo real.

Así este lugar en tanto agujero en el discurso, legitimaría la vía por la cual Freud hace hincapié con su frase: Wo Es war, soll Ich werden ${ }^{24}$ y que Lacan lo analiza en términos de que, en aquello sido hay algo que se dice, por lo tanto, si eso sido ya no es pero había sido, como el enunciado de aquello sido que habla, retorna y se actualiza. Si hay un movimiento de lo sido que deviene y aparece en su actualización de ser, simultáneamente en el tránsito de llegar a ser y transformarse, se da una desaparición, una negación que mantiene un intervalo en el decir. Sería una enunciación que se acusa y se renuncia disipando la ignorancia y dejando la traza de la diferencia, de la des-ligazón que une pero también provoca la escansión de la alteridad.

"Nous contentant d'un pas dans sa grammaire: là où ce fut...
qu'est-ce à dire? Si ce n'était que ça qui eût été, comment venir
là même pour m'y faire être de l'énoncer maintenant? Mais le
français dit: Là où c'était à l'instant même, là où c'était pour
un peu, entre cette extinction qui luit encore et cette éclosion
qui achoppe, je peux venir à l'être de disparaître de mont dit»» ${ }^{25}$

Sostengo que esta fórmula revelaría el momento escéptico en su máxima expresión, puesto que si la muerte, entendida en cuanto una "escritura" escéptica, oscila entre la posibilidad y la imposibilidad y se elaboraría a partir de una negatividad entre lo sido y el ser, es decir, en el siendo, por otra parte la negatividad se dejaría guiar por un movimiento que va retornando hacia un poder que no es sino lo afirmativo. Desde este punto de vista la muerte, entonces, como lenguaje scripturaire, a saber, como negatividad en sí misma, no se cumple plenamente sino a condición de mantenerse en el intervalo,

24 LACAN, Jacques, "Subversion du sujet et dialectique du désir dans I'inconscient freudien». En Ecrits. Du Seuil, Paris. 1966. Pág. 801.

25 Ibídem. 
en la diferencia ontológicamente hegeliana. En consecuencia, lo que habría que resaltar es el carácter fundamental que procede de una relación infinita y cuyo soporte sería a través del ejercicio de la reflexión en sentido hegeliano. Más aun, este acto de reflexión no es sino una actividad de poner representaciones que, desde el punto de vista de la alienación entre el "ça" y el moi, dirá Lacan:

«la formule de Freud -là où le ça était, le moi doit être- (....) le «ça» se réduit en fin de compte à un acte de mirage. L'ego se voit dans un soi qui n'est qu'une dernière aliénation de luimême, plus perfectionnée seulement que toutes celles qu'il a connues jusque-là» ${ }^{26}$

De momento cabría señalar, a propósito del análisis hecho por Lacan del ejemplo de Freud sobre la figura del padre muerto y que il ne savait pas qu'il était mort ${ }^{27}$ que la relación entre el je y lo sido, no tiene aquí una connotación temporal sino dialéctica, en la medida que es el je quien viene al lugar de lo sido. Si la frase comporta una ignorancia que "era" y que deviene un saber: el saber que el je meure ${ }^{28}$, entonces lo que intenta esclarecer Lacan es el estatuto del Ser del no-siendo.

En otras palabras, si existe un siendo que va deviniendo y cuyo contenido es el saber del paso del ser al no-ser y, por lo mismo, de la identidad de ambos, del cual el resultado es el siendo, esto también permite un saber de la diferencia inscrita internamente entre el ser y el no-ser. He ahí, lo que podría confirmar la idea hegeliana de la identidad de la identidad y la no-identidad. Donde el Ser del no-siendo expresaría la unidad de la diferencia interna de lo sido, a saber, el no siendo y su actualidad, que al mismo tiempo se va aboliendo. En consecuencia, es este movimiento el que legitima la muerte como aquello que sostiene la estructura que define el significante y el sujeto del mismo.

Finalmente y para concluir, al momento que Lacan introduce por primera vez la fórmula que definiría el significante, haciendo del sujeto

26 LACAN, Jacques. "Le Séminaire livre VI: le désir et son interprétation». Inedit cours du 9 juin 1954. Pág. 257.

27 LACAN, Jacques, «Subversion du sujet et dialectique du désir dans I'inconscient freudien». In Ecrits. Du Seuil, Paris. 1966. Pág. 802.

28 Ibídem. 
un elemento en su estructura, su operación teórica permitirá abrirse a la idea de que la relación entre significante y significado confirma un excedente que expresa la transgresión propia del siendo en su devenir. Lo que conllevaría la idea de que en dicha relación se manifiesta un desastre que daría significación al corte o escisión de la unidad y del "origen" en la base de la estructura. En aquello, igualmente, la experiencia scripturaire de la muerte en el inconsciente se fundaría sobre la brecha que podríamos llamar el desastre de la nominación, puesto que allí, la figura del desastre, haría su aparición tanto del impoder como al impoder y es esta reciprocidad la que expresaría una relación infinita inscrita como escepticismo.

\section{Bibliografía}

1.- BALMES, François; Structure, logique et alienation: recherches en psychanalyse, Editions érès. Scripta. Collection de I'Ecole de Psychanalyse Sigmund Freud. París/ Francia. 2011.

2.- FREUD, Sigmund; L'interprétation du rêves, traduction inédite par JeanPierre Lefebvre. Du Seuil Editions, París/Francia. 2010.

3.- FREUD, Sigmund; Inhibition, symtôme et angoisse, en Obras completas infobase en CD.

4.- FREUD, Sigmund; Le moi et le ça, en Obras completas infobase en CD.

5.- HEGEL, G.W.F.; La Fenomenología del espíritu; Fondo de Cultura Económica. 2da reimp. Bogotá Colombia, 1993.

6.- HEGEL, G.W.F.; Science de la Logique, premier tome - la logique objective, deuxième livre: La doctrine de l'essence. Traduction, présentation, notes par Gwendoline Jarczyk et Pierre-Jean Labarrière. Editions Kimé, París, 2010.

7.- HEGEL. G.W.F.; La relation du scepticisme avec la philosophie suivi de l'essence de la critique philosophique; Librairie philosophique J. Vrin, París/France. 1986.

8.- MALABOU, Catherine; Les nouveaux blessés de Freud à la neurologie, penser les traumatismes contemporaines. Bayard Editions, París/France, 2007.

9.- LACAN, Jacques; Ecrits, Du Seuil. París/France, 1966.

10.- LACAN, Jacques; Le Seminaire VII: I'ethique de la psychanalyse, Du Seuil, Paris/France, 1986

11.- LACAN, Jacques; Le Seminaire XI: Les quatre concepts fondamentaux de la psychanalyse, Du Seuil, París/France, 1966. 
12.- LACAN, Jacques; Seminario XI: Los cuatro conceptos fundamentales del psicoanálisis; Paidós, 1 ra edición, 18 reimpresión. Buenos Aires, 2011.

13.- QUENTIN, Bertrand; Hegel et le scepticisme; L'Harmattan, París/France. 2008.

14.- ROGOZINSKI, Jacob; Faire part, cryptes de Derrida. Lignes Editions, París/ France, 2005. 